\title{
Air purification from process emissions from electroplating baths
}

\author{
Anna Lifanteva ${ }^{1}$, Alsu Yusupova $^{1}$, and Galina Medvedeva*2[0000-0002-3507-606X] \\ ${ }^{1}$ Kazan National Research Technological University, 420015 Kazan, Russia \\ ${ }^{2}$ Kazan State University of Architecture and Engineering, 420043 Kazan, Russia
}

\begin{abstract}
Electroplating technology is an important technological process at production facilities of various profiles. The electroplating baths are a source of hazardous emissions of toxic vapors and aerosols. In factories with electroplating sites, the crucial task is to eliminate hazardous emissions by applying an effective exhaust ventilation and air purification system for subsequent air discharge into the atmosphere. In this article two basic schemes for cleaning process emissions from electroplating baths were developed: a scheme with purification in scrubbers; a scheme with purification in scrubbers with pre-filtration. The advantages and disadvantages of each scheme were considered. Based on the amount of hazardous emissions and their dispersed composition, the purification efficiency of each scheme was calculated using the probabilistic method. In view of the calculations, a scheme for cleaning process emissions from the electroplating line with the highest purification efficiency has been identified.
\end{abstract}

Keywords. Toxic vapors, aerosols, scrubber, pre-filtration, probabilistic method.

\section{Introduction}

At present, electroplating lines are an integral part of the technological process at production facilities of various profiles. Electroplating lines are used to obtain protective and decorative coatings of products. Cold nickel plating is used to obtain wear- and corrosion-resistant coating. The electrolyte used for nickel plating is a solution consisting of nickel sulfate, sodium hydroxide and sulfuric acid [1].

However, these substances that improve the product characteristics are toxic to a person working at the electroplating site. Sodium hydroxide (also known as caustic soda) is especially toxic to the human body [2]. It can lead to burns of the skin and mucous membranes, as well as respiratory tract and lung cancers. In this respect, it is particularly necessary to remove hazardous substances from the air of the working area on electroplating lines, including nickel-plating lines [3-5].

The removal of contaminated air is carried out by an exhaust mechanical ventilation system - lateral exhaust hood - followed by subsequent filtration to ensure that no hazardous substances get into the atmosphere.

*Corresponding author: medvedevaga79@mail.ru 
Wet scrubbing is the best way to remove the substances released from emissions from electroplating baths. Chemical oxidation of a gas flow through contact of a gas with liquid during wet scrubbing is the most preferred option [6-8]. Hollow scrubbers have the simplest wet treatment scheme with cleaning dusty gas flows. Hollow scrubbers have the following advantages: mass transfer capacity and integration of mixing, mass transfer, reaction and separation processes [9-11]. The design consists of circular columns, in which the gases to be purified are in contact with liquid drops irrigated by nozzles. In the majority of cases, a design is used in which gases and liquids move in opposite directions to each other. With this design, a droplet separator is installed in the upper part of the scrubber, and a drainage water tank in the lower part [12].

However, scrubbers do not provide emission purification to the required maximum allowable concentrations (MACs) in the ambient air when there is a large amount of emitted hazardous substances.

Scrubbing can be more effective when alkali (e.g., sodium hydroxide) is used as a fluid for the irrigation of gases $[13,14]$. When combining alkali and acid, a neutralization reaction occurs, during which salt and water are formed. Sodium hydroxide acts as an absorbing substance when capturing acid vapors. To reach effective absorption capacity, it is necessary to calculate the required fluid flow based on the amount of acid vapors entering the scrubber [15].

To improve the air purification, a filter can be added to the filtration system prior to the scrubbers, which more effectively captures fine particles of metal aerosols. Process emissions from nickel-plating baths contain hard-to-remove fine aerosol particles that must be treated in fibrous filters. [16]. Fibrous filter materials capture aerosol particles of micron and submicron sizes [17]. That is why fibrous filter materials prevail when choosing the filter type in the electroplating industry.

Numerous options for filtration of process emissions from electroplating baths are available, but there are no universal methods and equipment for purifying due to differences in technological processes in a particular production: different composition of hazardous substances and their mass, as well as the different temperature of the electroplating process.

Along with the high demand for nickel plating, there is a high demand for air purification from hazardous emissions [18]. However, enterprises are increasingly faced with low efficiency of treatment of process emissions [19].

The main aims of this research are design and selection of equipment, e.g., filter and scrubber, that is necessary for effective air purifying to eliminate acid vapors and aerosols on the nickel-plating line, because the need for explosion safety of airspace both inside and outside the building (in the atmosphere) is a pressing problem.

The main goals of this research are calculating the purification efficiency by the probabilistic method [20] and identifying the most effective air filtration scheme to eliminate acid vapors and aerosols on the nickel-plating line.

So, to make the goal real, the following tasks were addressed: two basic schemes for the treatment of process emissions in scrubbers were developed and considered, their purification efficiency was calculated and the most effective air filtration scheme was identified.

\section{Materials and methods}

\subsection{Experiment}

The research was carried out for the nickel-plating line of the electroplating section. The technological process consists of the application of a nickel layer on the product in an electroplating bath by applying nickel in a nickel sulfate electrolyte. The composition and amount of hazardous substances released during this process are indicated in Table 1. 
Table 1. Name and amount of hazardous substances.

\begin{tabular}{|c|c|}
\hline Name & Amount, g/sec \\
\hline $\mathrm{Ni}$ & 0.00192 \\
\hline $\mathrm{NaOH}$ & 0.264 \\
\hline $\mathrm{H}_{2} \mathrm{SO}_{4}$ & 0.0112 \\
\hline
\end{tabular}

The maximum allowable concentrations (MACs) in the air for these substances are shown in Table 2. The capacity of the local exhaust system for this line is $21020 \mathrm{~m}^{3} / \mathrm{h}$. According to these data, the final concentration of hazardous emissions entering the scrubber is indicated in Table 3. The amount of emitted hazardous substances exceeds the MAC. On this basis, it is required to design a local exhaust system with subsequent filtration of the process emission.

Table 2. Maximum allowable concentration of hazardous substances (MAC), $\mathrm{mg} / \mathrm{m}^{3}$.

\begin{tabular}{|c|c|}
\hline Name & MAC, $\mathbf{m g} / \mathrm{m}^{3}$ \\
\hline $\mathrm{Ni}$ & 0.001 \\
\hline $\mathrm{NaOH}$ & 0.5 \\
\hline $\mathrm{H}_{2} \mathrm{SO}_{4}$ & 1 \\
\hline
\end{tabular}

Table 3. Concentration of released hazardous substances, $\mathrm{mg} / \mathrm{m}^{3}$.

\begin{tabular}{|c|c|}
\hline Name & Concentration, $\mathrm{mg} / \mathrm{m}^{3}$ \\
\hline $\mathrm{Ni}$ & 0.33 \\
\hline $\mathrm{NaOH}$ & 45.23 \\
\hline $\mathrm{H}_{2} \mathrm{SO}_{4}$ & 1.9 \\
\hline
\end{tabular}

\subsection{Scheme of cleaning process emissions in scrubbers}

Fig. 1 shows a scheme of the process emission filtration system in scrubbers. According to Fig. 1, hazardous emissions are sucked in by the lateral exhaust hood, pass through the airduct and enter the scrubber. Inside, gas and aerosols flow through the air distributor plate and are irrigated with water. Gas and water then pass through the droplet separator. The dust particles are captured by liquid droplets and settled at the bottom of the drainage water tank. The purified air is removed from the apparatus.

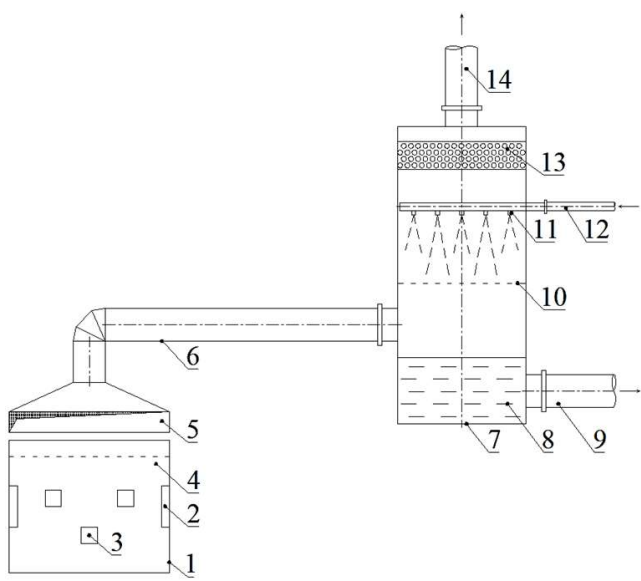

Fig. 1. Basic scheme of the process emission filtration system in scrubbers: 1 - electroplating bath; 2 - anode; 3 - cathode (product); 4 - electrolyte; 5 - lateral exhaust hood; 6 - air-duct (process emissions inlet); 7 - scrubber; 8 - drainage; 9 - drainage pipe; 10 - air distributor plate; 11 - irrigation nozzles; 12 - irrigation water supply; 13 - droplet separator; 14 - purified air discharge. 
Calculation of the dust and gas flow purification efficiency in the scrubber and calculation of the final concentration of hazardous emissions in the purified air [20]:

Required purification efficiency, $\%$ :

$$
\begin{gathered}
\varepsilon=\left[1-\frac{C_{\text {final }}}{C_{\text {initial }}}\right] \cdot 100 \%, \\
\varepsilon_{N i}=\left[1-\frac{0.001}{0.33}\right] \cdot 100 \%=99.7 \%, \\
\varepsilon_{N a O H}=\left[1-\frac{0.05}{45.23}\right] \cdot 100 \%=98.9 \%, \\
\varepsilon_{H 2 S O 4}=\left[1-\frac{1}{1.9}\right] \cdot 100 \%=47.4 \%,
\end{gathered}
$$

where $C_{\text {final }}$ - concentration of hazardous emissions after purification, equal to the MAC (Table 2), $\mathrm{mg} / \mathrm{m}^{3} ; C_{\text {initial }}$ - initial concentration of hazardous emissions (Table 3 ), $\mathrm{mg} / \mathrm{m}^{3}$.

Median particle diameter, depending on the dispersed composition of hazardous emissions, $\mu \mathrm{m}$ :

$$
d=\frac{\sum_{i=1}^{3}\left(g_{i} \cdot d_{i}\right)}{\sum_{i=1}^{3} g_{i}}
$$

Table 4. Dispersed composition of hazardous emissions.

\begin{tabular}{|c|c|c|c|}
\hline Name & $\mathbf{g , ~} \%$ & $\mathbf{d}, \boldsymbol{\mu m}$ & Density, $\mathbf{~ g} / \mathbf{m}^{\mathbf{3}}$ \\
\hline $\mathrm{Ni}$ & 0.8 & $45-71$ & 3.7 \\
\hline $\mathrm{NaOH}$ & 95.3 & $0.3-5.0$ & 2.13 \\
\hline $\mathrm{H}_{2} \mathrm{SO}_{4}$ & 4 & $1-1.5$ & 1.83 \\
\hline
\end{tabular}

$$
d=\frac{48.5 \cdot 0.8+2.6 \cdot 95.3+1.2 \cdot 4}{0.8+95.3+4}=\frac{291.4}{100.1}=2.91 \mu \mathrm{m}
$$

We shall accept: gas velocity in scrubber $w=1 \mathrm{~m} / \mathrm{sec}$, pressure drop $\Delta P=200 \ldots 250 \mathrm{~Pa}$, specific irrigation of gas $m=1 \cdot 10^{-3} \mathrm{~m}^{3} / \mathrm{m}^{3}$, droplet diameter $d_{d}=1 \cdot 10^{-3} \mathrm{~m}$, droplet sedimentation rate $w_{d}=1.1 \mathrm{~m} / \mathrm{sec}$.

Average scrubber area in cross-section perpendicular to the direction of gas flow, $\mathrm{m}^{2}$ :

$$
F=\frac{V_{g}}{w^{\prime}}
$$

where $V_{g}-$ local exhaust system performance.

Apparatus radius, diameter and height, $\mathrm{m}$ :

$$
F=\frac{21020}{1 \cdot 3600}=5.84 \mathrm{~m}^{2} \text {. }
$$

$$
\begin{gathered}
R=\left(\frac{F}{\pi}\right)^{0.5}, \\
D=2 \cdot R \\
h=2.5 \cdot D \\
R=\left(\frac{5.84}{3.14}\right)^{0.5}=1.36 \mathrm{~m}, \\
D=2 \cdot 1.36=2.72 \mathrm{~m} \\
h=2.5 \cdot 2.72=6.8 \mathrm{~m} .
\end{gathered}
$$

Fluid consumption for irrigation, $\mathrm{m}^{3} / \mathrm{sec}$ :

$$
\begin{gathered}
L=m \cdot V_{\Gamma}, \\
L=1 \cdot 10^{-3} \cdot 5.84=0.00584 \frac{\mathrm{m}^{3}}{\mathrm{sec}} .
\end{gathered}
$$

Inertial parameters $\psi$ for particle fractions of a given composition:

$$
\begin{gathered}
\psi=\frac{d^{2} \cdot \rho \cdot w \cdot C_{i}^{\prime}}{18 \cdot \mu \cdot l} \\
\psi_{N i}=\frac{\left(48.5 \cdot 10^{-6}\right)^{2} \cdot 3700 \cdot 1 \cdot 1}{18 \cdot 19.3 \cdot 10^{-6} \cdot 10^{-3}}=25.05,
\end{gathered}
$$




$$
\begin{aligned}
& \psi_{\mathrm{NaOH}}=\frac{\left(2.6 \cdot 10^{-6}\right)^{2} \cdot 2130 \cdot 1 \cdot 1}{18 \cdot 19.3 \cdot 10^{-6} \cdot 10^{-3}}=0.016 \\
& \psi_{\mathrm{H} 2 \mathrm{SO} 4}=\frac{\left(1.2 \cdot 10^{-6}\right)^{2} \cdot 1830 \cdot 1 \cdot 1}{18 \cdot 19.3 \cdot 10^{-6} \cdot 10^{-3}}=0.006
\end{aligned}
$$

Coefficients of the capture of particles of certain fractions for counterflow irrigation in a scrubber:

$$
\begin{aligned}
\eta & =\frac{\psi^{2}}{(\psi+0.35)^{2}}, \\
\eta_{N i} & =\frac{25.05^{2}}{(25.05+0.35)^{2}}=0.97, \\
\eta_{N a O H} & =\frac{0.016^{2}}{(0.016+0.35)^{2}}=0.0019, \\
\eta_{H 2 S O 4} & =\frac{0.006^{2}}{(0.006+0.35)^{2}}=0.00028 .
\end{aligned}
$$

Partial purification coefficient:

$$
\begin{gathered}
\varepsilon_{\phi}=1-\exp \left[-\frac{3 \cdot L \cdot \eta_{i} \cdot\left(w+w_{\mathrm{K}}\right) \cdot h}{2 \cdot V \cdot d \cdot w_{\mathrm{K}}}\right], \\
\varepsilon_{\phi N i}=1-\exp \left[-\frac{3 \cdot 0.00584 \cdot 0.97 \cdot(1+1.1) \cdot 6.8}{2 \cdot 5.84 \cdot 1 \cdot 10^{-3} \cdot 1.1}\right]=-1.64 \\
\varepsilon_{\phi N a O H}=1-\exp \left[-\frac{3 \cdot 0.00584 \cdot 0.0019 \cdot(1+1.1) \cdot 6.8}{2 \cdot 5.84 \cdot 1 \cdot 10^{-3} \cdot 1.1}\right]=0.94 \\
\varepsilon_{\phi H 2 S O 4}=1-\exp \left[-\frac{3 \cdot 0.00584 \cdot 0.00028 \cdot(1+1.1) \cdot 6.8}{2 \cdot 5.84 \cdot 1 \cdot 10^{-3} \cdot 1.1}\right]=0.999 .
\end{gathered}
$$

Overall purification coefficient of a hollow scrubber:

$$
\begin{gathered}
\varepsilon_{\text {total }}=\sum_{i=1}^{3} \frac{\eta \cdot g}{100} \\
\varepsilon_{\text {total }}=\frac{-1.64 \cdot 0.8}{100}+\frac{0.994 \cdot 95.3}{100}+\frac{0.999 \cdot 4}{100}=0.974=97.4 \% .
\end{gathered}
$$

Final concentrations in the gas flow:

$$
\begin{aligned}
& C_{\mathrm{KNi}}=C_{\mathrm{HNi}}\left(1-\varepsilon_{\text {total }}\right)=0.33 \cdot(1-0.974)=0.00858 \frac{\mathrm{mg}}{\mathrm{m}^{3}}>\frac{0.001 \mathrm{mg}}{\mathrm{m}^{3}}, \\
& C_{\mathrm{KNaOH}}=C_{\mathrm{HNaOH}}\left(1-\varepsilon_{\text {total }}\right)=45.23 \cdot(1-0.974)=1.175 \frac{\mathrm{mg}}{\mathrm{m}^{3}}>\frac{0.5 \mathrm{mg}}{\mathrm{m}^{3}}, \\
& C_{\mathrm{KH} 2 \mathrm{SO}_{4}}=C_{\mathrm{HH} 2 \mathrm{SO} 4}\left(1-\varepsilon_{\text {total }}\right)=1.9 \cdot(1-0.974)=0.0494 \frac{\mathrm{mg}}{\mathrm{m}^{3}}<\frac{1 \mathrm{mg}}{\mathrm{m}^{3}} .
\end{aligned}
$$

Purification efficiency in a hollow scrubber is insufficient, since the final concentration of nickel aerosol and sodium hydroxide vapor after purifying exceeds the MAC. It should be taken into account that the purification efficiency obtained by theoretical calculation is less as a matter of practice. In this process emission purification scheme, nickel and caustic soda are deposited in large amounts into the scrubber's drainage water tank after irrigation. The precipitated impurities must be removed from the drainage water, it additionally loads the drainage filtration system. It is necessary to use a more efficient treatment scheme for process emissions.

\subsection{Scheme of cleaning process emissions in scrubbers with pre-filtration}

Fig. 2 shows a scheme of the process emission filtration system in scrubbers with prefiltration in fibrous filters. According to Figure 2, hazardous emissions are sucked in by the lateral 
exhaust hood, pass through the fibrous filter and enter the scrubber. Inside, gas and aerosols flow through the air distributor plate and are irrigated with water. Gas and water then pass through the droplet separator. The dust particles are captured by liquid droplets and settled at the bottom of the drainage water tank. The purified air is removed from the apparatus.

The most common aerosol filter is a fibrous filter made of synthetic fibers, which are chemically resistant to acids, alkalis and salt solutions. Taking into account the dispersed composition of the hazardous emissions indicated in Table 3, it is necessary to install a coarse filter with a fiber blend diameter from 1 to 20 microns. Large diameter particles are almost completely captured in the filter and smaller diameter particles with partial clogging from 50 to $99 \%$ [12].

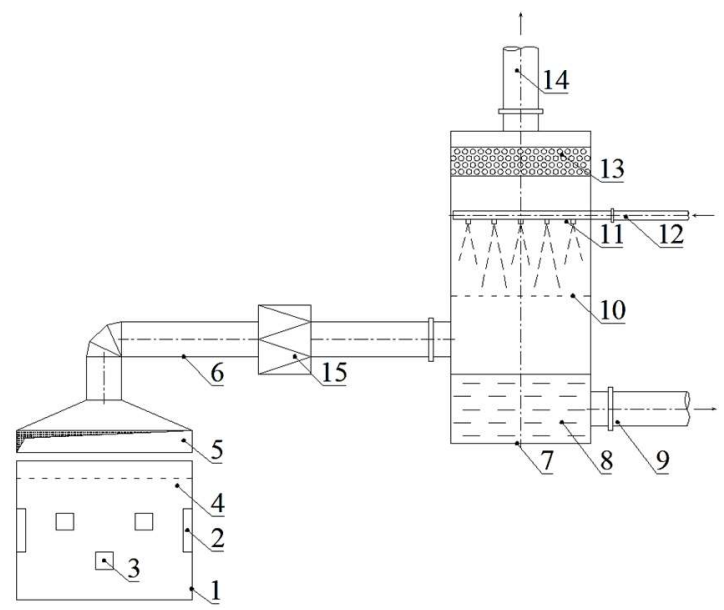

Fig. 2. Basic scheme of the process emission filtration system in scrubbers with pre-filtration: $1-$ electroplating bath; 2 - anode; 3 - cathode (product); 4 - electrolyte; 5 - lateral exhaust hood; 6 - airduct (process emissions inlet); 7 - scrubber; 8 - drainage; 9 - drainage pipe; 10 - air distributor plate; 11 - irrigation nozzles; 12 - irrigation water supply; 13 - droplet separator; 14 - purified air discharge; 15 - filter.

To calculate the purification efficiency of the fibrous filter, we shall accept that the breakthrough coefficient for nickel aerosol particles with a size of 48.5 microns is $1 \%$, and for particles of sodium hydroxide and sulfuric acid vapor $-30 \%$. The filter efficiency was determined based on the initial $\mathrm{C}_{\text {initial }}$ and the final $\mathrm{C}_{\text {final }}$ concentrations of hazardous emissions before and after filtration, respectively, $\mathrm{mg} / \mathrm{m}^{3}$, as well as the percentage of hazardous emissions in the mixture (Table 3) and the breakthrough coefficient P, \% [21].

$$
\begin{gathered}
\eta=\sum \frac{100-\Pi}{100} \cdot g \\
\mathrm{C}_{\text {final }}=C_{\text {initial }} \cdot \frac{\Pi}{100} \\
\mathrm{C}_{\mathrm{KNi}}=0.33 \cdot \frac{1}{100}=0.01 \frac{\mathrm{mg}}{\mathrm{m}^{3}}>\frac{0.001 \mathrm{mg}}{\mathrm{m}^{3}}, \\
\mathrm{C}_{\mathrm{KNaOH}}=45.23 \cdot \frac{30}{100}=13.57 \frac{\mathrm{mg}}{\mathrm{m}^{3}}>\frac{0.5 \mathrm{mg}}{\mathrm{m}^{3}}, \\
\mathrm{C}_{\mathrm{KH} 2 S O 4}=1.9 \cdot \frac{30}{100}=0.57 \frac{\mathrm{mg}}{\mathrm{m}^{3}}<\frac{1 \mathrm{mg}^{3}}{\mathrm{~m}^{3}} \\
\eta=\frac{100-1}{100} \cdot 0.8+\frac{100-30}{100} \cdot 95.3+\frac{100-30}{100} \cdot 4=70.3 \% .
\end{gathered}
$$

The filter efficiency amounted to $70.3 \%$. The concentration of hazardous substances in the air after passing through the coarse fibrous filter has decreased, which makes it possible 
to reduce the load on the scrubber. The concentration of sulfuric acid vapors decreased to a value less than the MAC after filtration.

Required purification efficiency, \%:

$$
\begin{aligned}
\varepsilon_{N i} & =\left[1-\frac{0.001}{0.01}\right] \cdot 100 \%=90 \%, \\
\varepsilon_{N a O H} & =\left[1-\frac{0.05}{13.57}\right] \cdot 100 \%=99.6 \% .
\end{aligned}
$$

where $C_{\text {final }}$ - concentration of hazardous emissions after purification, equal to the MAC (Table 2), $\mathrm{mg} / \mathrm{m}^{3} ; C_{\text {initial }}$ - initial concentration of hazardous emissions (Table 5), $\mathrm{mg} / \mathrm{m}^{3}$.

Table 5. Concentrations of released hazardous substances after filtration, $\mathrm{mg} / \mathrm{m}^{3}$.

\begin{tabular}{|c|c|}
\hline Name & Concentration, $\mathbf{~ m g} / \mathbf{m}^{\mathbf{3}}$ \\
\hline $\mathrm{Ni}$ & 0.01 \\
\hline $\mathrm{NaOH}$ & 13.57 \\
\hline $\mathrm{H}_{2} \mathrm{SO}_{4}$ & $0.57<\mathrm{MAC}$ \\
\hline
\end{tabular}

Median particle diameter, depending on the dispersed composition of hazardous emissions, $\mu \mathrm{m}$ :

$$
d=\frac{48.5 \cdot 0.8+2.6 \cdot 95.3+1.2 \cdot 4}{0.8+95.3+4}=\frac{291.4}{100.1}=2.91 \text { microns. }
$$

Average scrubber area in cross-section perpendicular to the direction of gas flow, $\mathrm{m}^{2}$ :

$$
F=\frac{21020}{1 \cdot 3600}=5.84 \mathrm{~m}^{2} \text {. }
$$

Apparatus radius, diameter and height, $\mathrm{m}$ :

$$
\begin{aligned}
R & =\left(\frac{5.84}{3.14}\right)^{0.5}=1.36 \mathrm{~m}, \\
D & =2 \cdot 1.36=2.72 \mathrm{~m} \\
h & =2.5 \cdot 2.72=6.8 \mathrm{~m} .
\end{aligned}
$$

Fluid consumption for irrigation, $\mathrm{m}^{3} / \mathrm{sec}$ :

$$
L=1 \cdot 10^{-3} \cdot 5.84=0.00584 \frac{\mathrm{m}^{3}}{\mathrm{sec}}
$$

Inertial parameters $\psi$ for particle fractions of a given composition:

$$
\begin{gathered}
\psi_{N i}=\frac{\left(48.5 \cdot 10^{-6}\right)^{2} \cdot 3700 \cdot 1 \cdot 1}{18 \cdot 19.3 \cdot 10^{-6} \cdot 10^{-3}}=25.05, \\
\psi_{N a O H}=\frac{\left(2.6 \cdot 10^{-6}\right)^{2} \cdot 2130 \cdot 1 \cdot 1}{18 \cdot 19.3 \cdot 10^{-6} \cdot 10^{-3}}=0.016, \\
\psi_{H 2 S O 4}=\frac{\left(1.2 \cdot 10^{-6}\right)^{2} \cdot 1830 \cdot 1 \cdot 1}{18 \cdot 19.3 \cdot 10^{-6} \cdot 10^{-3}}=0.006 .
\end{gathered}
$$

Coefficients of capture of particles of certain fractions for counterflow irrigation in a scrubber:

Partial purification coefficient:

$$
\begin{gathered}
\eta_{N i}=\frac{25.05^{2}}{(25.05+0.35)^{2}}=0.97 \\
\eta_{N a O H}=\frac{0.016^{2}}{(0.016+0.35)^{2}}=0.0019, \\
\eta_{H 2 S O 4}=\frac{0.006^{2}}{(0.006+0.35)^{2}}=0.00028 .
\end{gathered}
$$

$$
\varepsilon_{\phi N i}=1-\exp \left[-\frac{3 \cdot 0.00584 \cdot 0.97 \cdot(1+1.1) \cdot 6,8}{2 \cdot 5.84 \cdot 1 \cdot 10^{-3} \cdot 1.1}\right]=-1.64,
$$




$$
\begin{gathered}
\varepsilon_{\phi N a O H}=1-\exp \left[-\frac{3 \cdot 0.00584 \cdot 0.0019 \cdot(1+1.1) \cdot 6.8}{2 \cdot 5.84 \cdot 1 \cdot 10^{-3} \cdot 1.1}\right]=0.94, \\
\varepsilon_{\phi H 2 S O 4}=1-\exp \left[-\frac{3 \cdot 0.00584 \cdot 0.00028 \cdot(1+1.1) \cdot 6.8}{2 \cdot 5.84 \cdot 1 \cdot 10^{-3} \cdot 1.1}\right]=0.999 .
\end{gathered}
$$

Overall purification coefficient of a hollow scrubber:

$$
\varepsilon_{\text {total }}=\frac{-1.64 \cdot 0.8}{100}+\frac{0.994 \cdot 95.3}{100}+\frac{0.999 \cdot 4}{100}=0.974=97.4 \%
$$

Final concentrations in the gas flow:

$$
\begin{aligned}
& C_{\mathrm{KNi}}=C_{\mathrm{HNi}}\left(1-\varepsilon_{\text {total }}\right)=0.01 \cdot(1-0.974)=0.00026 \frac{\mathrm{mg}}{\mathrm{m}^{3}}<\frac{0.001 \mathrm{mg}}{\mathrm{m}^{3}}, \\
& C_{\mathrm{KNaOH}}=C_{\mathrm{HNaOH}}\left(1-\varepsilon_{\text {total }}\right)=13.57 \cdot(1-0.974)=0.35 \frac{\mathrm{mg}}{\mathrm{m}^{3}}<\frac{0.5 \mathrm{mg}}{\mathrm{m}^{3}}, \\
& C_{\mathrm{KH} 2 S O 4}=C_{\mathrm{HH} 2 S O 4}\left(1-\varepsilon_{\text {total }}\right)=0.57 \cdot(1-0.974)=0.015 \frac{\mathrm{mg}}{\mathrm{m}^{3}}<\frac{1 \mathrm{mg}}{\mathrm{m}^{3}}
\end{aligned}
$$

The concentration of hazardous substances decreased to values less than the MAC after the coarse fibrous filtration and wet scrubbing. Additional equipment for air purification is not required. The concentrations of hazardous substances are significantly reduced after passing the filter, which means that nickel and sodium hydroxide will be deposited into the scrubber's drainage water tank in insignificant amounts after irrigation. As a result, the load on the drainage filtration system is reduced.

\section{Results and discussion}

To purify the process emissions from hazardous substances on the nickel-plating line, 2 basic schemes were developed. According to the first scheme, the released mixture is purified in a scrubber, when the second scheme suggests to purify the mixture in a wet scrubber with the preliminary cleaning in a coarse fibrous filter.

The result of the probabilistic calculation of the scrubber and the calculation of the final concentration of emitted substances for scheme 1 is indicated in Table 6. As follows from the calculation, the final concentrations of hazardous emissions exceed the MAC, which is a violation under the current hygienic standards. The air after such a purification will pollute the atmosphere, and be explosive due to the toxicological characteristics of the substances included in the composition. The final concentration of sulfuric acid after cleaning in a scrubber decreased to values less than the MAC, however, the concentration of aerosol nickel and sodium hydroxide did not decrease to the required values. Drainage water must be

\begin{tabular}{|c|c|c|c|}
\hline Name & $\begin{array}{l}\text { Initial concentration, } \\
\mathrm{mg} / \mathrm{m}^{3}\end{array}$ & $\begin{array}{c}\text { Final concentration, } \\
\mathrm{mg} / \mathrm{m}^{3}\end{array}$ & $\begin{array}{l}\text { Maximum allowable } \\
\text { concentration, } \mathrm{mg} / \mathrm{m}^{3}\end{array}$ \\
\hline $\mathrm{Ni}$ & 0.33 & 0.0086 & 0.001 \\
\hline $\mathrm{NaOH}$ & 45.23 & 1.175 & 0.5 \\
\hline $\mathrm{H}_{2} \mathrm{SO}_{4}$ & 1.9 & 0.0494 & 1 \\
\hline
\end{tabular}
purified from nickel and sodium hydroxide deposited in high concentrations, that is why an efficient and energy-intensive drainage water treatment system is required.

The purification in scrubber is effectless for the nickel-plating line upon the given parameters.

Table 6. Concentration of hazardous substances in the air using $1^{\text {st }}$ treatment scheme, $\mathrm{mg} / \mathrm{m}^{3}$.

Following scheme 2, the released mixture passes through two stages of purification: preliminary - in a coarse fibrous filter and the second-cleaning in a wet scrubber.

The results of calculating the filter efficiency, the probabilistic calculation of the scrubber and the calculation of the final concentration of emitted substances for scheme 2 are indicated 
in Table 7. As follows from the calculation, the final concentration of sulfuric acid after purification in a scrubber decreased to values less than the MAC, the concentration of aerosol nickel and sodium hydroxide did not decrease to the required values. After the second stage - cleaning in a wet scrubber - the final concentrations of hazardous emissions decreased to values less than the MAC, which corresponds to the current hygienic standards.

Nickel and sodium hydroxide are also deposited in the scrubber drainage tank, but in much smaller amounts than in scheme 1 due to pre-filtration of process emissions in the fiber filter. The same efficient drainage water treatment system is required, but for the operation of such a system, fewer reagents are used.

The developed purification scheme for the nickel-plating line upon the given parameters is effective. The use of a fibrous filter for coarse cleaning and a scrubber in production makes the discharged air purified and explosion-proof.

Table 7. Concentration of hazardous substances in the air using $2^{\text {nd }}$ treatment scheme, $\mathrm{mg} / \mathrm{m}^{3}$.

\begin{tabular}{|c|c|c|c|c|}
\hline Name & $\begin{array}{c}\text { Initial } \\
\text { concentration, } \\
\mathbf{m g} / \mathbf{m}^{\mathbf{3}}\end{array}$ & $\begin{array}{c}\text { Concentration } \\
\text { after filter, } \\
\mathbf{m g} / \mathbf{m}^{\mathbf{3}}\end{array}$ & $\begin{array}{c}\text { Concentration } \\
\text { after scrubber, } \\
\mathbf{m g} / \mathbf{m}^{\mathbf{3}}\end{array}$ & $\begin{array}{c}\text { Maximum allowable } \\
\text { concentration, } \\
\mathbf{m g} / \mathbf{m}^{\mathbf{3}}\end{array}$ \\
\hline $\mathrm{Ni}$ & 0.33 & 0.01 & 0.00026 & 0.001 \\
\hline $\mathrm{NaOH}$ & 45.23 & 13.57 & 0.35 & 0.5 \\
\hline $\mathrm{H}_{2} \mathrm{SO}_{4}$ & 1.9 & 0.57 & 0.015 & 1 \\
\hline
\end{tabular}

\section{Conclusion}

The industrial facility must comply with the applicable hygienic standards. In work areas where electroplating is applied hazardous toxic substances are emitted. In this connection, there is the need for an effective process emission treatment system with the lowest power consumption.

It is essential to select a scheme for air purification from hazardous substances, which depends on the technological process in the electroplating area. To ensure the required standards, the initial concentrations of the emitted hazardous substances, their disperse composition, density and the MACs are taken into account when selecting the scheme.

It is also important to consider that the proposed air purification system should have the minimum possible effect on the operation of other systems, such as the drainage treatment system.

The first purification scheme has a few disadvantages: the final concentrations of hazardous substances in the air are higher than the MAC. This scheme is unacceptable with the sanitary and hygienic standards. Hygienic standards are not met. Also, after irrigation, nickel and sodium hydroxide are deposited in large amounts into the scrubber's drainage water tank. There is need for a drainage treatment system that will effectively treat wastewater with reagents, which leads to additional resource consumption.

The second treatment scheme has fewer disadvantages for the reason that the final concentrations of all hazardous substances emitted into the air are reduced to values less than the MAC. This scheme complies with the sanitary and hygienic standards but requires more costs as a fibrous filter is added to the scheme. For wastewater treatment with impurities of sodium hydroxide and nickel fewer reagents are required.

Including or excluding additional equipment to/from the treatment scheme also leads to a change in the purification efficiency. That is why calculation of the purification efficiency by the probabilistic method allows determining the most appropriate method of process emission filtration emitted from the electroplating baths when selecting the purification scheme for a particular technological process.

The second treatment scheme is the most appropriate for the case considered in this research, which is the nickel-plating line. At the first cleaning stage (the fibrous filter), the cleaning efficiency amounted to $70.3 \%$, at the second stage (in the scrubber) $-97.4 \%$. 


\section{References}

1. P.K. Lavorko, Manual for the master of the electroplating shop. M.: Publishing House «Mechanical engineering», 272 (1969).

2. O.D. Volkov, Design of ventilation of an industrial building. Kharkiv: Publishing house association «Vyshcha shkola», 240 (1989).

3. V.I. Ilyin, A.F. Gubin. Astrakhan Bulletin of environmental education 55, (2014).

4. Yu.M. Averina, G.E. Kalyakina, V.V. Menshikov, Yu.I. Kapustin, V.S. Boldyrev. Bulletin of the MSTU. N.E. Bauman 70, (2019). DOI: 10.18698/1812-3368-2019-3.

5. R.A. Kovalev, M.G. Burdova, I.V. Grishina. Bulletin of the Tula State University 343, (2018).

6. C. Liang, Y.J. Chen, K.J. Chang, J. Hazard. Mater 164, 2 (2009). DOI: 10.1016/j.jhazmat. 2008.08.056.

7. R.B. Lawson. J. Air Waste Manage 49, 1315 (1999). DOI: 10.1080/10473289.1999. 10463959.

8. J.R. Kastner, K.C. Das. J. Air Waste Manage. Assoc. 52, 459 (2002). DOI: 10.1080/ 10473289.2002.10470800.

9. Q. Zhao, X. Quan, Z. Cheng, J. Yan. J. Chem. Indus. Eng. Soc. China 64, 3993 (2013).

10. X. Quan, F. Wang, Q. Zhao, T. Zhao, J.J. Hazard. Mater 170, 983 (2009). DOI: 10.1016/ j.jhazmat.2009.05.083.

11. F. Wang, X. Quan, Q. Zhao, T.J. Chem. Indus. Eng. Soc. China 60, 1186 (2009).

12. M.I. Birger, Handbook of dust and ash collection. M.: Energoatomizat, 312 (1983).

13. F. Rahmani, D. Mowla, G. Karimi, A. Golkhar. Sep. Purif. Technol 153, 162 (2015). DOI: $10.1016 /$ j.seppur.2014.10.028.

14. H.H. Park, B.R. Deshwal, I.W. Kim, H.K. Lee. J. Membr. Sci. 319, 29 (2008).

15. P.C. Chen, C.F. Huang, H.W. Chen, M.W. Yang, C.M. Tsao. Energy Procedia 61, 1660 (2014).

16. M.G. Ziganshin, A.M. Ziganshin. Izvestija KGASU 11, 181 (2009).

17. E.R. Daniel, A.Z. Manuel Separation and Purification Technology 257, 14 (2021). DOI: 10.1016/j.seppur.2020.117676.

18. A.V. Sharafutdinova. Izvestija KGASU 7, 94 (2007).

19. M. Andrus. Metal finishing 107, 19 (2009).

20. A.G. Vetoshkin. Penza: PSUP, 210 (2005).

21. I.G. Kobzar, V.V. Kozlova, Processes and apparatuses of environmental protection. Ulyanovsk: U1STU, 68 (2007). 